This is the first draft of the document. To see the full paper please visit:

https://doi.org/10.1016/j.jclepro.2020.122401

\title{
Tube shelters from agricultural plastic waste: an example of circular economy
}

\section{J. Martínez Urreaga ${ }^{1,2}$, F.R. Beltrán ${ }^{1,2}$, J. Acosta ${ }^{2,3}$, T. Aguinaco ${ }^{2,3}$, C. Fonseca ${ }^{2,3}$, A. Ochoa ${ }^{2,3}$,} J. A. Oliet Palá ${ }^{4}$, C. González-Sánchez ${ }^{5}$, M.U. de la Orden ${ }^{2,6}$

${ }^{1}$ Dpto. Ingeniería Química Industrial y del Medio Ambiente, E.T.S.I. Industriales, Universidad Politécnica de Madrid, José Gutiérrez Abascal, 2, 28006-Madrid, Spain.

${ }^{2}$ Grupo de Investigación: Polímeros, Caracterización y Aplicaciones (PolCA).

${ }^{3}$ E.T.S. de Ingeniería y Diseño Industrial, Universidad Politécnica de Madrid

${ }^{4}$ E.T.S. de Ingeniería de Montes, Forestal y del Medio Natural, Universidad Politécnica de Madrid

${ }^{5}$ Dpto. Ingeniería Química y TMA, Facultad de Química, Universidad de Oviedo

${ }^{6}$ Dpto. de Química Orgánica, Facultad de Óptica y Optometría, Universidad Complutense de Madrid

Corresponding author email: joaquin.martinez@upm.es

\section{Abstract}

The use of recycled plastics in applications similar to those of the original plastic is of great interest for the fulfillment of the circular economy policies objectives. In this work, the feasibility of using recycled agricultural plastics in the manufacture of tube shelters for plant seedlings, which can be used in forest restoration and other plantations, has been investigated. The recycled plastics and their blends with a virgin polyethylene were characterized using spectroscopic techniques and thermal analysis. The effects of the recycled plastics on the optical and mechanical properties of the blends, which are key properties in the selection of materials for tube shelters, were measured using UV-Vis spectroscopy and tensile testing. Thermal stability and degradation during an accelerated aging test were also investigated. The use of recycled plastics did not alter the stability of the blends, but there were decreases in elongation at break and UV and blue light transmission, with small decreases in red light transmission and without significant changes in the red-far red ratio. Blends with less than $50 \mathrm{wt} \%$ of recycled plastics show only small decreases in the elongation and provide an adequate light transmission for seedlings. Therefore, the results indicate that significant amounts of recycled agricultural plastics can be used in the manufacture of tube shelters, with clear environmental advantages.

Keywords: agricultural plastic waste, mechanical recycling, circular economy, tube shelters, light transmission.

\section{Abbreviation list}

ATR Attenuated total reflectance

CE Circular economy

DSC Differential scanning calorimetry

EVA Ethylene-vinyl acetate copolymer

FTIR Fourier transform infrared spectroscopy

HALS Hindered amine light stabilizers

HDPE High-density polyethylene

LDPE Low-density polyethylene

LLDPE Linear low-density polyethylene 


$\begin{array}{rll}1 & \text { PAR } & \text { Photosynthetically active radiation } \\ 2 & \text { PLA } & \text { Poly(lactic acid) } \\ 3 & \text { R-FR } & \text { Red/far-red ratio } \\ 4 & \text { RH } & \text { Relative humidity } \\ 5 & \text { TGA } & \text { Thermogravimetric analysis } \\ 6 & \mathrm{~T}_{5} & \text { Temperature at which } 5 \% \text { of the mass is lost } \\ 7 & \mathrm{~T}_{\max } & \text { Temperature of maximum rate of mass loss } \\ 8 & \mathrm{~T}_{\mathrm{m}} & \text { Melting temperature } \\ 9 & \mathrm{UV} & \text { Ultraviolet } \\ 10 & \mathrm{Vis} & \text { Visible } \\ 11 & \Delta \mathrm{H}_{\mathrm{m}} & \text { Melting enthalpy }\end{array}$

\section{Introduction}

The production and consumption of plastics continues to increase worldwide, due to the important advantages of these materials in packaging, textile, automotive, agriculture and other applications (Nature Comm., 2018). Most of these plastics are not biodegradable and are obtained from non-renewable sources, mainly crude oil, so that their high consumption results in serious issues, such as the depletion of raw materials or the need to manage large amounts of very stable waste (Ragossnig and Schneider, 2019; Ellen MacArthur Foundation, 2016).

At present, the most important fates for plastics waste are landfill, energy recovery and recycling (Plastics Europe, 2018). Still a significant amount of waste, about 20\%, ends up in unmanaged dumps, which causes major environmental problems (Hundertmark et al., 2018). Among the possible destinations, the most interesting is recycling, because it allows reducing the consumption of raw materials and energy associated with the manufacture of virgin polymers, while reducing the volume of waste that can cause environmental problems. Gu et al. have recently carried out a life cycle assessment of the mechanical recycling of plastic waste coming from agriculture and other sources, based on real-world data; their results show that mechanical recycling is a superior alternative for the wastes in most environmental aspects $(\mathrm{Gu}$ et al., 2017). Hou et al. have obtained similar results in their study of the environmental impacts of various plastic film waste treatment systems; recycling shows a considerable advantage over incineration or landfill disposal, mainly due to the use of recycled plastics instead of plastics produced from virgin raw materials (Hou et al., 2018). Plastic waste recycling offers other additional advantages such as creating jobs, generating sustainable growth and boosting the competitiveness of the industrial companies (Andreoni et al., 2015; Arenas-Vivo et al., 2017). It should also be noted that mechanical recycling preserves the possibility of energy recovery when the recycling of waste is no longer viable. So, mechanical recycling of waste plastics plays a main role in achieving the objectives of the circular economy (CE) policy, one of the keys of the European policy for the coming years (Leal Filho et al., 2019; European Commission, 2018).

Agriculture is one of the main applications of plastics (Rentizelas et al., 2018; ScarasciaMugnozza et al., 2011). Currently about $3.4 \%$ of all plastic produced goes to agriculture in Europe (Plastics Europe, 2018), for instance in the form of film for applications such as greenhouses, tunnels, mulching and silage (Briassoulis et al., 2013). The use of plastic covers presents important advantages in agriculture, since it allows to control the temperature and the incoming solar radiation, while reducing the need for energy and the consumption of water, fertilizers and pesticides. Only in Spain, more than 220,000 $\mathrm{t}$ of plastic were used in agriculture in 2015, including more than 90,000 t of agricultural plastic film (ANAIP, 2019). The polymers most used in agricultural films are low-density polyethylene (LDPE) and linear low-density polyethylene (LLDPE), with minor amounts of ethylene-vinyl acetate (EVA) copolymer 
(Briassoulis et al., 2013; La Mantia, 2010). Other polymers, such as high-density polyethylene (HDPE), polypropylene (PP) and poly(vinyl chloride) (PVC), are used in structures, pipes and other applications.

The high consumption of plastics in agriculture makes the fate of agricultural plastics waste (APW) an important environmental issue and a problem for the fulfillment of the objectives set out in the CE policies. Several studies have shown that mechanical recycling is a viable alternative for many APWs because recycled plastics with good properties can be obtained (Briassoulis et al., 2013, Picuno et al., 2012, González-Sánchez et al., 2014). Currently, a portion of the waste generated is mechanically recycled and marketed for different applications. The highest quality recycled plastic is used, for example, in the manufacture of recycled film for applications such as mulching, pipes and garbage bags. APW is also recycled to be used in the manufacture of plastic lumber, which is used in applications such as deck floors, fences, park benches and other outdoor furniture.

However, the APW fraction subjected to mechanical recycling is still a minority due to some problems, among which the following can be highlighted:

- The cost of collection, separation, cleaning and reprocessing is rather high, so sometimes the cost of recycled plastic is similar to that of virgin plastic (or even higher, depending on the crude oil prices).

- The presence of different and immiscible polymers leads to recycled plastics with decreased performance.

- The presence of soil and other impurities, often in high proportions, increases the cost of cleaning and reduces the quality of the recycled plastic.

- The degradation suffered by the plastic during its useful life also reduces the quality of the recyclate.

- Some waste plastics show too high concentrations of agrochemicals, so they are considered hazardous.

In order to increase the mechanical recycling of APW, it is necessary to develop new viable markets for the recycled plastics, optimizing the economy of the recycling process and improving the performance of recycled plastic. The processes for improving the properties of recycled plastics must be simple, economical and environmentally sound. For example, previous works have shown that the properties of composite materials obtained from recycled agricultural plastics and residual cellulose can be improved by mixing with HDPE coming from urban plastic waste (Martínez Urreaga et al., 2015) and by the addition of small amounts of organic peroxides (González-Sánchez et al., 2016).

The development of new viable markets for recycled plastics also requires demonstrating the utility of recycled plastics in new applications. The present work addresses the study of the feasibility of using recycled plastics obtained from APW in the manufacture of tube shelters for seedlings in plantations. These tube shelters, which are widely used in new vineyards, forest restorations and other applications, are usually made from polymers such as PE or PP. The tubes play an important role in the survival and growth of planted seedlings, because they protect them from predators and control the amount of light reaching the plant, as well as the temperature and relative humidity inside the tube (Oliet et al., 2005; Puértolas et al., 2010). Some optical properties of plastic tube wall, such as amount and quality of transmitted light, can affect these microclimatic conditions, with consequences for seedlings survival and growth (Devine and Harrington 2008). Additionally, mechanical properties need to be characterized in order to validate the use of tested material in planting operations and its response to outdoor field conditions.

Two recycled agricultural plastics (RAP), both obtained by mechanical recycling of greenhouse covers and other used agricultural plastic films, and one virgin LDPE, were used in 
the study. Tubes with different LDPE-RAP ratio, obtained by melt compounding and blowing, were characterized in order to evaluate the suitability of the RAP to manufacture tube shelters. Structure and chemical composition were analyzed using differential scanning calorimetry (DSC) and Fourier Transform Infrared (FTIR) spectroscopy. The key properties of the tubes, i.e., tensile strength and elongation at break, thermal stability and light transmission, were measured using tensile tests, thermogravimetry (TGA) and UV-Vis spectroscopy, respectively. Finally, samples of the different tubes were compared after being subjected to accelerated aging. The performance of the tubes obtained from virgin LDPE and LDPE-RAP blends is similar; therefore, these results appear to indicate that significant amounts of APW can be used in the manufacture of tube shelters with good performance.

\section{Materials and methods}

\subsection{Materials}

The recycled agricultural plastics used in this work, Alfaten 200 (AF200) (GonzálezSánchez et al., 2014) and Alfaten 231 (AF231), were kindly supplied by Befesa Plásticos (now GW Plastics, Spain). AF200 was obtained by mechanical recycling of APW (mainly greenhouse covers, with some amounts of tunnel and mulching films generated in the southeast of Spain. AF231 was obtained by melt reprocessing of AF 200. Both recycled plastics are dark brown, because of the presence of impurities and some black plastic. The LDPE used as reference material was Alcudia PE003, a colorless plastic supplied by REPSOL (Spain).

The tubes of the desired composition, with wall thickness around $0.7 \mathrm{~mm}$, were obtained by extrusion and blowing, using a Covex single-screw tubular film extruder. The barrel temperatures, from hopper to die, were $150-155-160-165$ and $170{ }^{\circ} \mathrm{C}$. The code names of the RAP-LDPE blends are XXAF200 or XXAF231, were XX stands up for the wt \% of RAP in the blend.

Accelerated aging was carried out in an Angelantoni Discovery DY1200 climatic chamber. In order to compare the effects of temperature and humidity, samples were subjected to temperatures ranging from $-20^{\circ} \mathrm{C}$ until $80^{\circ} \mathrm{C}$ at relative humidities between 30 and $85 \%$, including $6 \mathrm{~h}$ of UV treatment. Specifically, each sample was subjected to the following cycle: $8 \mathrm{~h}$ at $-20{ }^{\circ} \mathrm{C}$ and $30 \% \mathrm{RH} ; 8 \mathrm{~h}$ at $80{ }^{\circ} \mathrm{C}$ and $30 \% \mathrm{RH} ; 8 \mathrm{~h}$ at $80^{\circ} \mathrm{C}$ and $85 \% \mathrm{RH} ; 8 \mathrm{~h}$ at $5{ }^{\circ} \mathrm{C}$ and $85 \% \mathrm{RH} ; 6 \mathrm{~h}$ at $35^{\circ} \mathrm{C}$ without RH control; $6 \mathrm{~h}$ of UV treatment at $35^{\circ} \mathrm{C}$ without $\mathrm{RH}$ control.

\subsection{Characterization Techniques}

Differential scanning calorimetry (DSC) was performed under nitrogen atmosphere on samples of about $5 \mathrm{mg}$, in standard aluminum pans, using a TA Instruments Q-20 calorimeter. Samples were heated from 30 to $180{ }^{\circ} \mathrm{C}$ at a rate of $5{ }^{\circ} \mathrm{C} / \mathrm{min}$ in the first heating scan. After 3 min at $180{ }^{\circ} \mathrm{C}$, samples were cooled until $-60{ }^{\circ} \mathrm{C}$, kept at $-60{ }^{\circ} \mathrm{C}$ for $1 \mathrm{~min}$ and then heated again, until $180^{\circ} \mathrm{C}$ (second heating). The values of melting temperature and melting enthalpy were determined in the second heating scan. In the thermogravimetric analysis (TGA), samples of 12-14 mg were heated at $10{ }^{\circ} \mathrm{C} / \mathrm{min}$ from room temperature to $800{ }^{\circ} \mathrm{C}$ in dry nitrogen $(30$ $\mathrm{cm}^{3} / \mathrm{min}$ ), using a TA Instruments TGA2050 thermogravimetric analyzer.

Infrared spectra were recorded in a Nicolet iS10 spectrometer, equipped with a diamond Attenuated Total Reflectance (ATR) accessory. Each spectrum was recorded at a resolution of $4 \mathrm{~cm}^{-1}$, with 16 scans. The FTIR-ATR spectra were corrected using the software supplied with the spectrophotometer. 
Transmission in the ultraviolet and visible regions was measured according to the ISO 13468 standard, using a Shimadzu 2401 PC UV-Vis spectrophotometer equipped with a Shimadzu integrating sphere, with a scan speed of $200 \mathrm{~nm} / \mathrm{min}$.

Tensile tests were performed using a Metrotec Hounsfield H10KT test machine, following the standard ISO 527 (Part 1). Test samples according to the standard ISO 3167 were used. Values reported are the average of measurements made on five specimens.

\section{Results and discussion}

\subsection{Characterization of the plastics}

Due to the presence of different polymers, additives and impurities, recycled plastics usually have a complex chemical composition (González-Sánchez et al., 2014), which must be studied because it determines the structure and, therefore, the optical, mechanical and thermal properties of the final product. The composition and structure of the starting recycled plastics used in this work, AF200 and AF231, and their blends with LDPE, were studied using FTIRATR spectroscopy and differential scanning calorimetry.

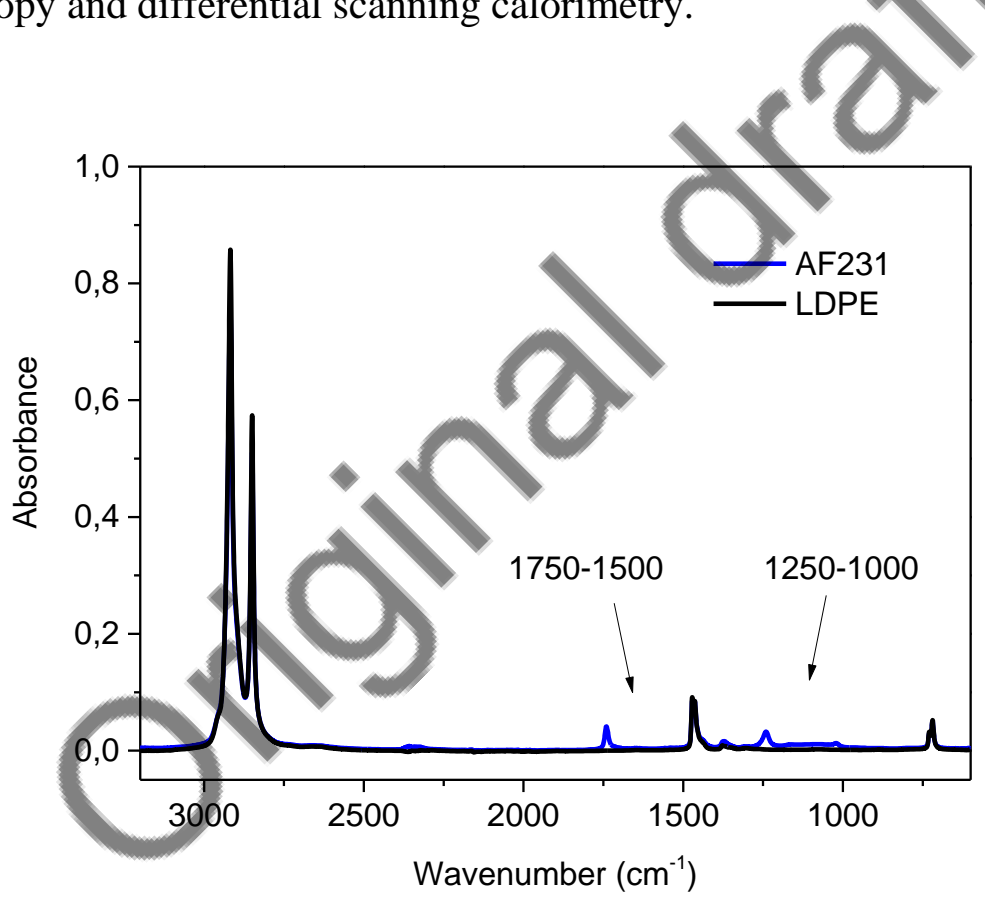

Fig. 1. FTIR-ATR spectra of the virgin plastic, LDPE, and one of the recycled plastics used, AF231.

Fig. 1 shows that the FTIR-ATR spectra of LDPE and AF231 are similar. The most abundant polymer in both cases is polyethylene, since the spectra show the PE characteristic absorption bands at 720-730 $\left(\mathrm{CH}_{2}\right.$ rocking $), 1460\left(\mathrm{CH}_{2}\right.$ bending $)$ and $2850-2920 \mathrm{~cm}^{-1}(\mathrm{CH}$ symmetric and asymmetric stretching). Some differences can also be observed, mainly in the 1750-1500 and the 1250-1000 $\mathrm{cm}^{-1}$ regions of the spectra, which are shown enlarged in Fig. 2.

Fig. 2 shows that the spectra of the blends with AF200 and AF231 are very similar. The strongest characteristic bands of both recycled plastics, and their blends with LDPE, appear at 1740 and $1240 \mathrm{~cm}^{-1}$. These absorptions can be assigned to the stretching modes of $\mathrm{C}=\mathrm{O}$ and $\mathrm{C}$ $\mathrm{O}$, respectively, of the acetate groups of ethylene-vinyl acetate copolymer (Martínez Urreaga et al., 2015). The presence of EVA in recycled agricultural plastics is explained by the use of this polymer in the formulation of plastics for greenhouse covers, due to its good mechanical 
properties and its contribution to the greenhouse effect (La Mantia, 2010). In a previous work, an analysis of recycled agricultural plastics revealed the presence of $2.5-4.5 \mathrm{wt} \%$ of EVA (González Sánchez et al., 2014).

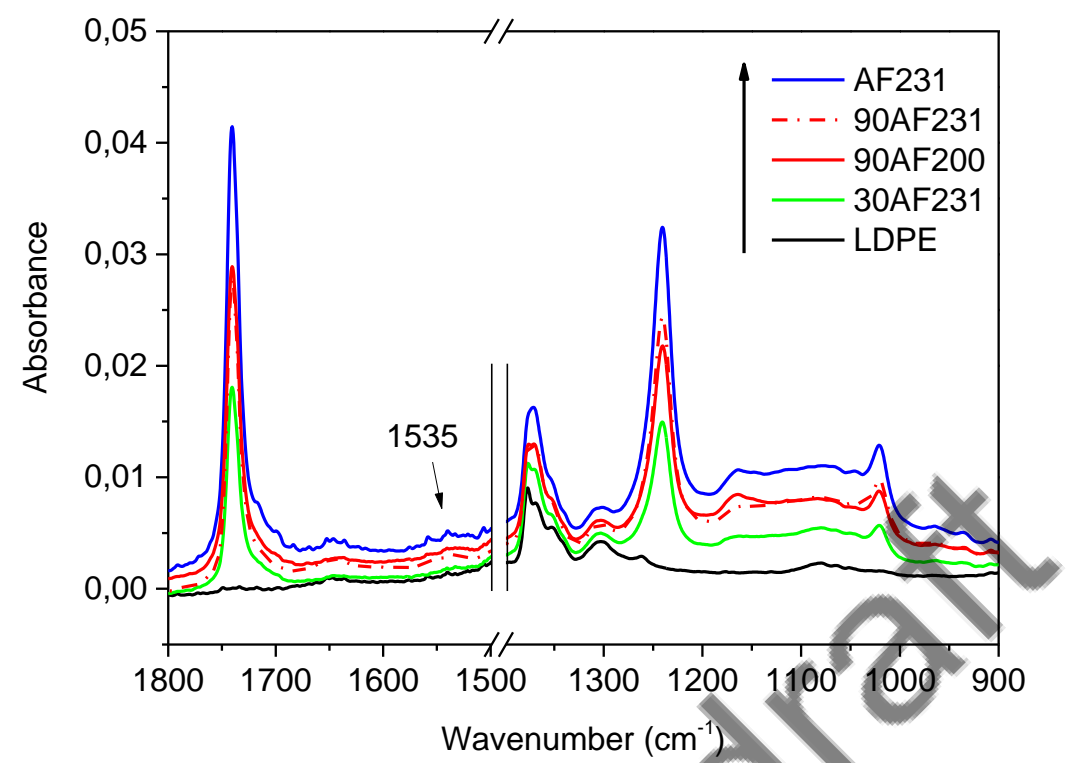

Fig. 2. FTIR-ATR spectra of LDPE, AF231 and their blends.

Spectra of the materials obtained from recycled plastics show other low-intensity bands that reveal the presence of additives that may be interesting for the applications of these plastics. A very weak band at $1535 \mathrm{~cm}^{-1}$ indicates the presence of hindered amine light stabilizers (HALS), a kind of additive widely used in greenhouse covers (Scoponi et al., 2000). This absorption is interesting because it reveals that a part of the photo-stabilization additives of agricultural plastics remains after their useful life and appears in the recycled plastics, providing resistance to degradation. The weak bands that appear between 1000 and $1200 \mathrm{~cm}^{-1}$ can be assigned to impurities, mainly soil, present in recycled plastics, but also to the presence of silicates such as talc or kaolin, which are used in greenhouse covers as additives for improving the greenhouse effect (La Mantia, 2010; Picuno et al., 2012). The presence of silicates and HALS increases the interest of agricultural recycled plastics in the manufacture of tube shelters, since they confer interesting properties such as stability and greenhouse effect. 


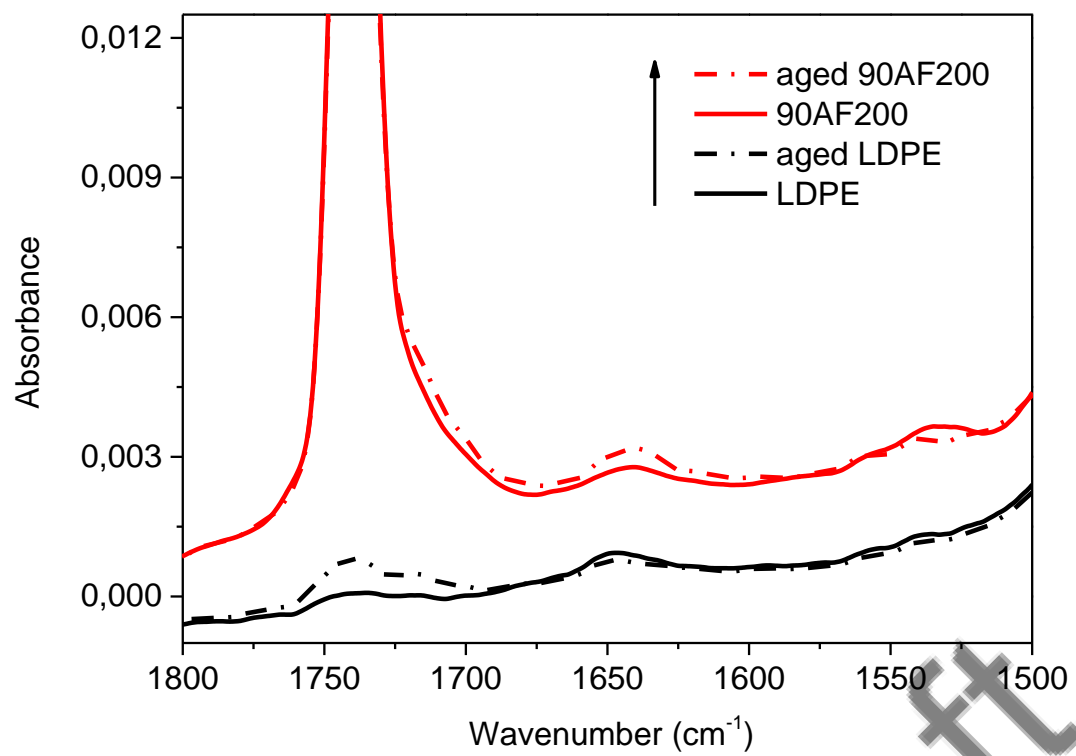

Fig. 3. FTIR-ATR spectra of LDPE and the blend with 90 wt \% of AF200, recorded before and after the accelerated ageing experiments.

FTIR spectroscopy also provides information on the chemical transformations of plastics during aging tests. Fig. 3 allows comparing the effect of the aging test on the spectra LDPE and 90AF200, the blend with $90 \mathrm{wt} \%$ of AF200. In both plastics the appearance of weak absorptions in the $1700-1740 \mathrm{~cm}^{-1}$ is observed, which can be assigned to new $\mathrm{C}=\mathrm{O}$ groups formed during the test. In addition, the blend shows a small increase in absorption at $1640 \mathrm{~cm}^{-1}$, which does not appear for the pure LDPE. This band could be due to the absorption of a small amount of water during the test, due to the presence of EVA, a polymer more hydrophilic than polyethylene. Anyway, it should be noted that the chemical changes are minimal, as can be observed in the values of the absorbances. The changes in the recycled plastic are even smaller than in the virgin, which may be due to the presence of stabilizing additives. The disappearance of the band centered at $1535 \mathrm{~cm}^{-1}$ in the aged blend can be related to the consumption of stabilizers during the aging tests. 


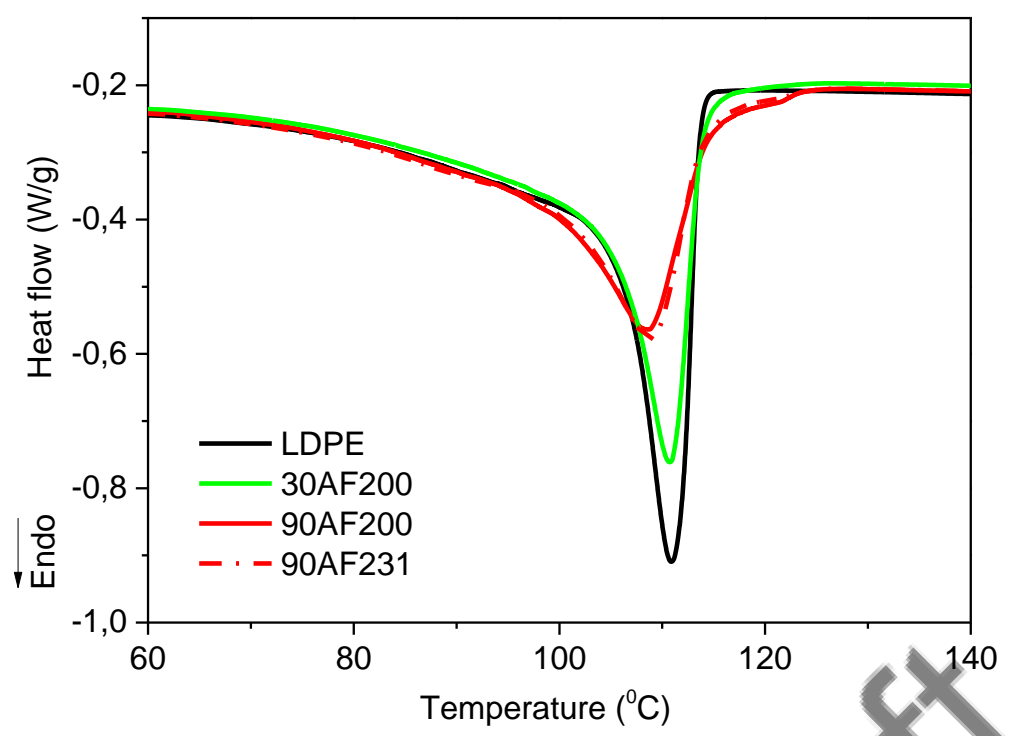

Fig. 4. DSC curves (first heating scan) corresponding to LDPE and different blends with AF200 and AF231.

The chemical nature of recycled plastics can also be studied by differential scanning calorimetry (DSC). Fig. 4 shows the DSC curves, corresponding to the first heating scan (the curves of the second heating scan are very similar), of virgin LDPE and different RAP-LDPE blends. The DSC curve of LDPE confirms that it is the pure polymer, since it only shows the characteristic melting endotherm of low-density polyethylene, with a melting temperature $T_{m}$ $=111.5{ }^{\circ} \mathrm{C}$. The presence of recycled agricultural plastic causes $\mathrm{T}_{\mathrm{m}}$ to decrease to $108.9{ }^{\circ} \mathrm{C}$, widens the melting endotherm and reduces the area under the curve, which measures the melting enthalpy $\left(\Delta \mathrm{H}_{\mathrm{m}}\right)$ and, therefore, the crystallinity of the material. The values of $\mathrm{T}_{\mathrm{m}}$ and $\Delta \mathrm{H}_{\mathrm{m}}$ are shown in Table 1 . The differences in the DSC curves of the recycled plastics can be explained considering that the presence of impurities and other polymers, such as EVA and LLDPE, hinders the crystallization of LDPE during the cooling of the melt, thus generating less perfect crystalline structures and in smaller proportion. The presence of EVA has been shown above by FTIR spectroscopy. The presence of LLDPE in recycled plastics is confirmed by a small melting peak observed at $120{ }^{\circ} \mathrm{C}$ in the DSC curves of the blends (Tzankova Dintcheva et al., 1997).

Table 1. DSC and TGA parameters of LDPE and different blends with AF200 and AF231.

\begin{tabular}{lccccc}
\hline & $\mathbf{T}_{\mathbf{m}}\left({ }^{\mathbf{0}} \mathbf{C}\right)$ & $\boldsymbol{\Delta H}_{\mathbf{m}}(\mathbf{J} / \mathbf{g})$ & $\mathbf{T}_{\mathbf{5}}\left({ }^{\mathbf{0}} \mathbf{C}\right)$ & $\mathbf{T}_{\max }\left({ }^{\mathbf{0}} \mathbf{C}\right)$ & Residue (wt \%) \\
\hline LDPE & 111.5 & 128 & 405.0 & 465.5 & 0.1 \\
\hline Aged LDPE & 111.2 & 126 & 390.6 & 455.4 & 0.9 \\
\hline 90AF200 & 108.9 & 119 & 396.0 & 477.7 & 2.3 \\
\hline Aged 90AF200 & 108.9 & 119 & 387.5 & 476.4 & 2.5 \\
\hline 90AF231 & 109.2 & 118 & 395.7 & 476.6 & 2.3
\end{tabular}

Materials subjected to the accelerated aging test show a different behavior in the first and the second heating scan, as can be seen in Fig. 5. In the DSC curve corresponding to the first heating, the samples subjected to the test show a splitting of the melting endotherms, with the 
appearance of a new maximum at temperatures as low as $88{ }^{\circ} \mathrm{C}$. A similar behavior has been previously observed in polyethylene samples subjected to thermal treatments and has been explained considering that the treatment causes a rearrangement of the crystalline structures, which leads to a segregation in structures of different sizes and different melting temperatures (Vallés-Lluch et al., 2002). As expected, this segregation cannot be observed in the second heating scan because the fusion erases the thermal history of the material. It is also worth to note that Fig. 5 confirms that the virgin plastic and the blends with recycled agricultural plastics behave in a very similar way.

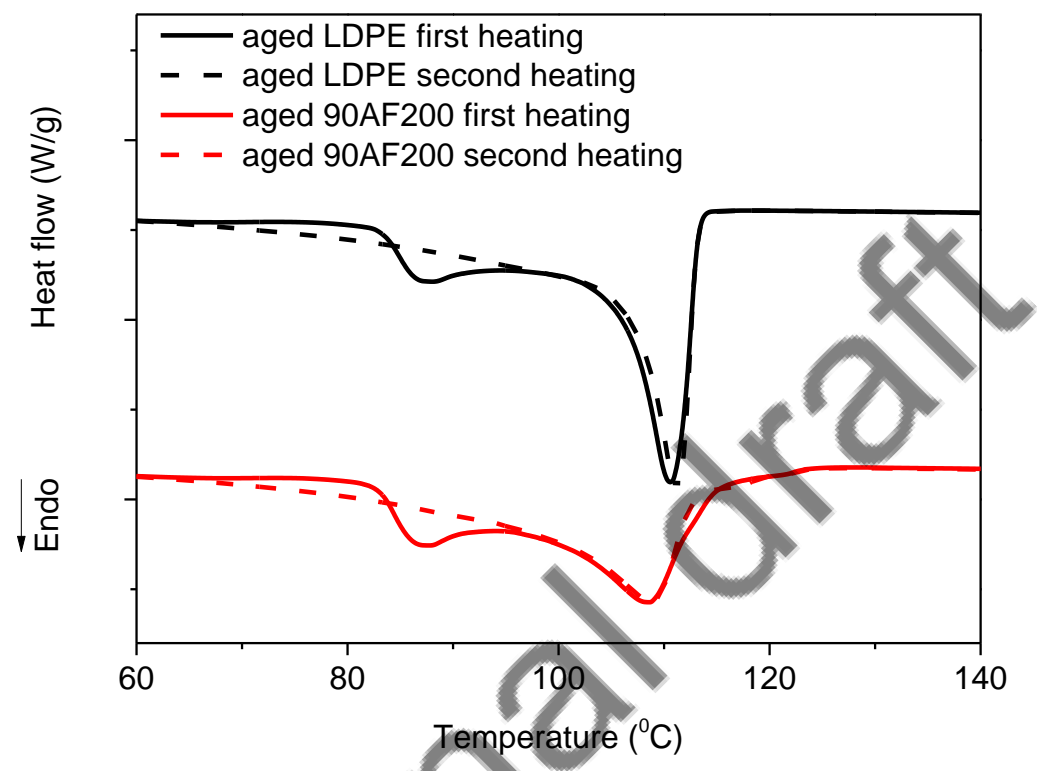

Fig. 5. DSC curves (first and second heating scans) corresponding to LDPE and a blend with AF200, measured after being subjected to accelerated aging.

\subsection{Properties of the blends}

The development of the use of a recycled plastic in a certain application, such as the manufacture of tube shelters, requires ensuring that the key properties of the final product will be at least similar to those of the product manufactured with virgin plastic. Therefore, the effect of recycled plastics on the most important properties when selecting a plastic to make tube shelters, that is, stability and mechanical and optical properties, has been investigated.

\subsubsection{Stability and mechanical properties}

The effect of the recycled plastics on the thermal stability of the blends has been investigated using thermogravimetric analysis. Fig. 6 shows the degradation curves of LDPE and the blends with a high content of AF200 and AF231, as well as the curves recorded after subjecting the materials to accelerated aging tests. Table 1 shows the values of the residue, i.e., the mass remaining after the thermal degradation, as well as those of two characteristic degradation temperatures. $\mathrm{T}_{5}$ is the temperature at which $5 \%$ of the initial mass has been lost by degradation and is frequently considered as a value representative of the initial degradation temperature. $\mathrm{T}_{\max }$ is the temperature at which the maximum speed of mass loss is reached. 


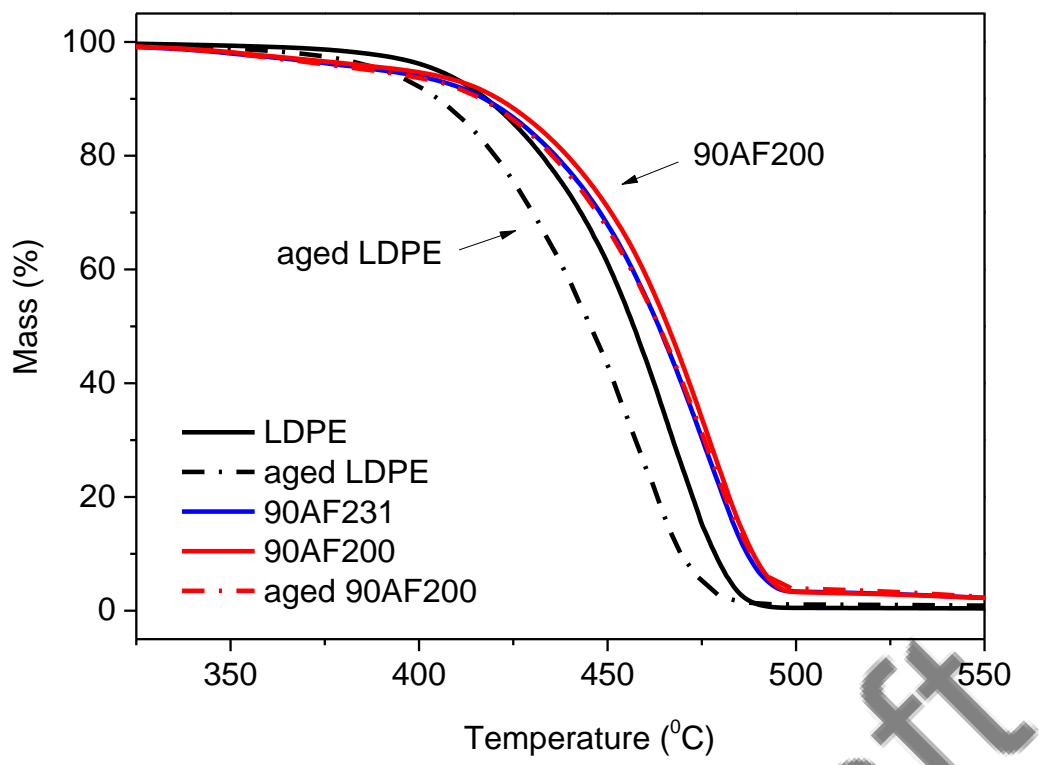

Fig. 6. TGA curves corresponding to LDPE and blends with 90 wt\% of AF200 or AF231.

Note: TGA curves corresponding to 90AF231 and aged 90AF200 are practically superimposed.

Fig. 6 and Table 1 show that the behavior of the blends during the thermal degradation is slightly different. While the TGA curves corresponding to LDPE show the loss of almost $100 \%$ of the initial mass in a single stage that starts at around $400{ }^{\circ} \mathrm{C}$, the curves of the blends show a small mass loss at lower temperatures, between 350 and $400{ }^{0} \mathrm{C}$. However, the total decomposition of the material takes place at temperatures higher than those observed for LDPE. In addition, the final mass in the TGA tests of the blends is not null, but a residue of more than $2 \mathrm{wt} \%$ is formed.

The mass loss step that appears at temperatures lower than $400{ }^{\circ} \mathrm{C}$, which reduces the initial degradation temperature by $9^{\circ} \mathrm{C}$, may be assigned, at least in part, to the decomposition of the EVA present in the recycled plastic. It is known that the thermal decomposition of EVALLDPE blends starts at $300-380{ }^{\circ} \mathrm{C}$ with a deacetylation process that produces acetic acid; the second step takes place at temperatures higher than $380{ }^{\circ} \mathrm{C}$ and involves the decomposition of the polyethylene macromolecules (Chuang et al., 2004). The thermal degradation of some impurities and additives of the recycled plastics may also contribute to the first mass loss step. Regarding the residues observed in Table 1 and Fig. 6 at temperatures higher than $500{ }^{\circ} \mathrm{C}$, it must be considered that some of the additives, such as talc and kaolin, and impurities, such as silica and silicates from soil, generate stable compounds under thermal treatments a $600{ }^{\circ} \mathrm{C}$, which may be responsible for the residues. In order to explain the greater overall thermal stability of blends with recycled plastic, which leads to a greater value of $\mathrm{T}_{\max }$, different factors have to be considered, among which the presence of LLDPE and stabilization additives in recycled plastics could be highlighted.

Fig. 6 and Table 1 also present the results corresponding to aged samples of LDPE and 90AF200. The accelerated aging causes a clear decrease in the thermal stability of pure LDPE, which leads to significant decreases, of more than $10{ }^{\circ} \mathrm{C}$, in both $\mathrm{T}_{5}$ and $\mathrm{T}_{\max }$. However, the effects of the same test on the thermal stability of the blend are less important. In this case, $\mathrm{T}_{5}$ decreases by $8.5^{\circ} \mathrm{C}$, but $\mathrm{T}_{\max }$ remains almost unchanged. The better behavior of the recycled plastic in the accelerated aging test, which is in good agreement with the results of the FTIR analysis of the aged samples, may be due to the presence of stabilization additives. 
The effects of the recycled plastics on the mechanical properties have been also studied because some properties, such as the tensile strength and the elongation at break, are very important when selecting plastics for the manufacture of tube shelters. Fig. 7 shows that the effect of the recycled plastics on the strength at break is small; the blends of LDPE with AF200 or AF231 generally show lower values than the pure LDPE, but the decreases are similar to the uncertainty of the measurements.

The elongation at break of the blends is clearly lower than that of the virgin plastic and decreases as the recycled plastic content increases, as can be seen in Fig. 8. This effect may be due to the presence of impurities that facilitate the breakage under stress and, also, to the degradation of the agricultural plastics during its useful life, which causes chain scission and cross-linking reactions that increase the brittleness of the material. However, it should be noted that the presence of the recycled plastics studied only causes moderate decreases, lower than $30 \%$. For instance, the blend with an AF231 content as high as 50\% shows a decrease in the elongation at break of only $18 \%$. These results suggest that blends of virgin LDPE with significant amounts of recycled agricultural plastics can meet the mechanical requirements of the plastics in many applications, so that great amounts of recycled plastics could be used in this kind of applications.

Fig. 7 and 8 also show the values of strength and elongation at break corresponding to aged samples of LDPE and 90AF200. In good agreement with the results obtained in the studies of thermal stability and chemical degradation, the accelerated aging test causes only small decreases in the mechanical properties of pure LDPE and, especially, 90AF200. For this blend, the decreases are very similar to the values of the uncertainty of the measurements, thus confirming the good stability of the blends of LDPE with recycled agricultural plastics.

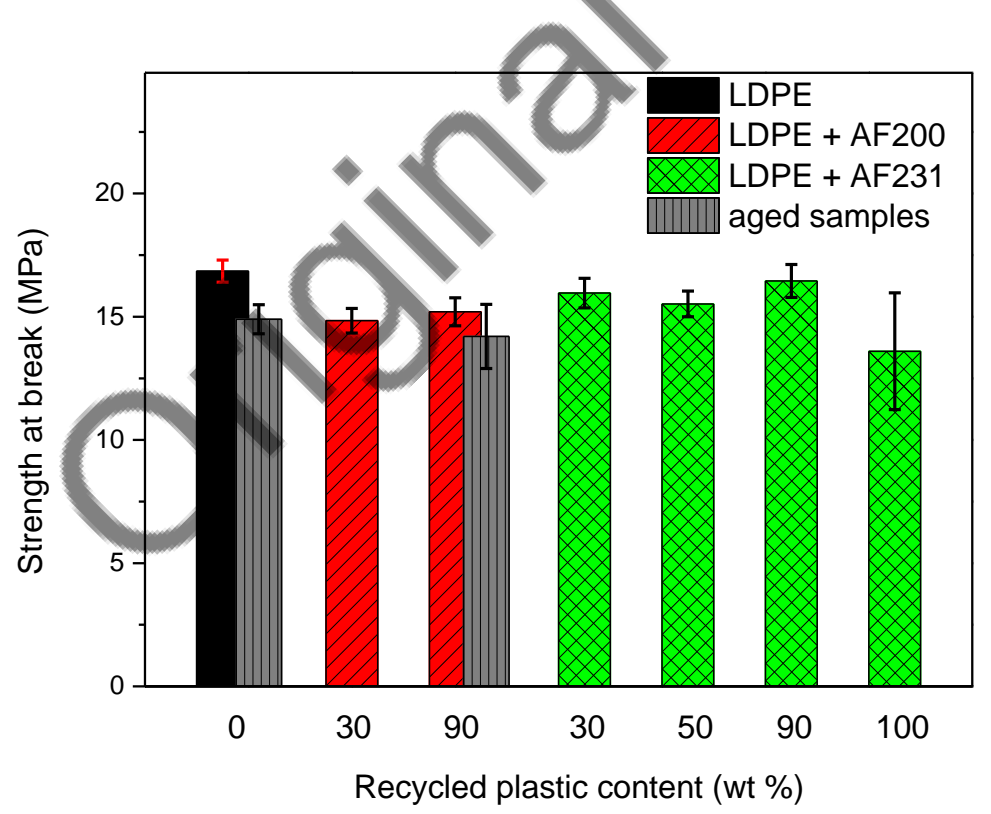

Fig. 7. Strength at break of LDPE and different blends with AF200 or AF231. The values corresponding to aged materials are also included. 


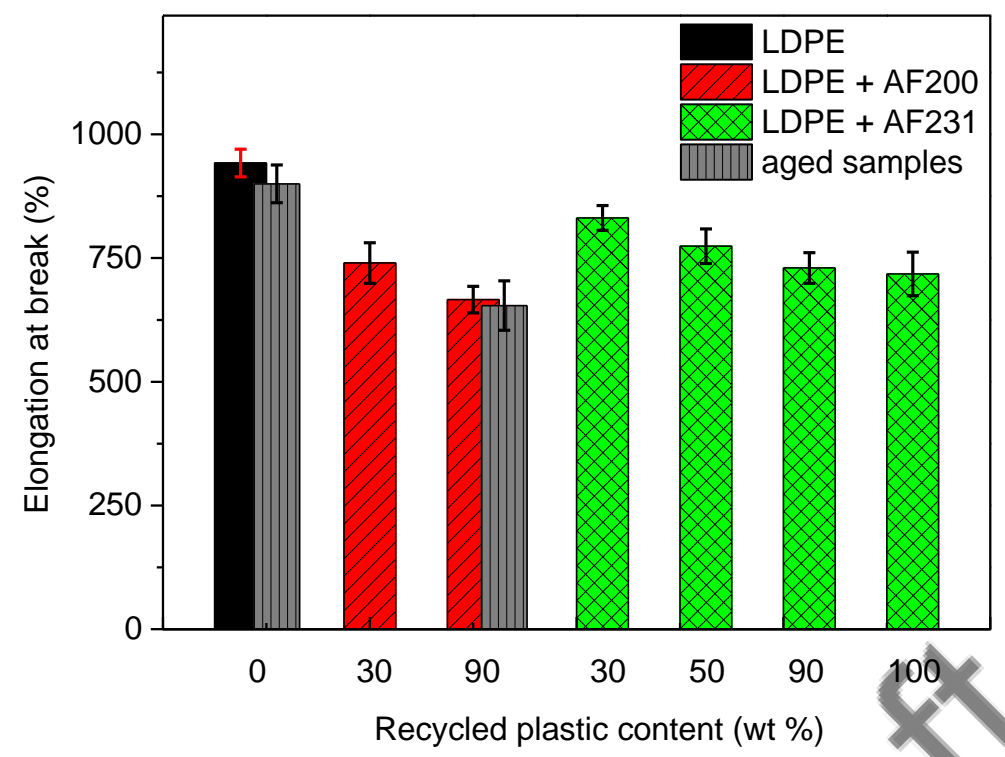

Fig. 8. Elongation at break of LDPE and different blends with AF200 or AF231. Grey bars correspond to aged samples of LDPE and 90AF200.

\subsubsection{Optical properties}

Optical properties play a main role in the performance of seedlings protected by tube shelters. Most of the studies concerning the effect of optical properties on plant development have focused on transmission in the whole photosynthetically active radiation (PAR) spectrum. This is the radiation that drives photosynthesis, with a spectral range very similar to that of visible light (400-700 nm) and both survival and growth of seedlings depend on the PAR light transmission of the shelter (Puértolas et al., 2010; Oliet et al., 2015). However, it must be taken into account that the spectral distribution of the visible light that passes through the walls of the shelter has a significant effect on the growth of the seedlings. In addition, other radiations, such as the low and mid-energy ultraviolet, could also have significant effects.

Fig. 9 shows the UV-Vis transmission spectra of virgin plastic and different blends with AF200 (blends with AF231 show similar spectra). The addition of recycled plastic causes a significant decrease of the whole transmission, due to the presence of impurities and black plastics that make it darker. In the visible light region, this reduction ranges from $10 \%$ (for a blend with $30 \mathrm{wt} \%$ of AF200) to $50 \%$ (blend with wt90\% of AF200). Although the effects of this transmission depends on the climate and functional attributes of the species, conducted studies in this regard show that a reduction of the visible light transmission between 20 and 60 $\%$ may be useful depending on shade-tolerance of the species in Mediterranean or other dry ecosystems (Vázquez de Castro et al., 2014). Thus, the recycled blends provide an appropriate light transmission range for our ecological planting conditions. 


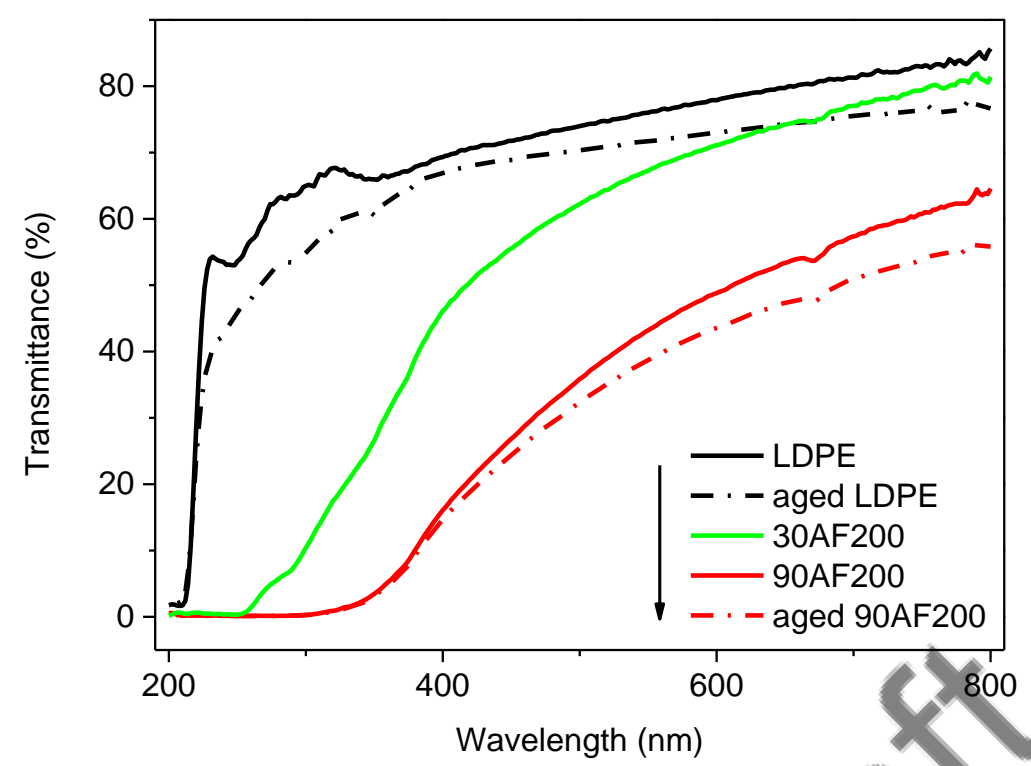

Fig. 9. UV-Vis transmission spectra of LDPE and different blends with AF200. Dashed lines correspond to aged samples of LDPE and 90AF200.

Light transmission also slightly decreases during the accelerated aging test (Fig. 9), which could be related to the rearrangement of the crystalline structures that takes place during the test. This rearrangement leads to a segregation in crystalline structures of different sizes, as it has been observed in the DSC curves of the aged samples, which could lead to an increase in the scattering of light and the consequent decrease in transmission.

Along with the reduction shown in the transmission in the whole spectrum, it is important to note that the decrease is not the same throughout the different spectral regions (Fig 10). In particular, light transmission drops sharply in the ultraviolet fraction (Fig. 9 and 10). For instance, an addition of $30 \mathrm{wt} \%$ of recycled plastic leads to a reduction of more than $68 \%$ of UV-A radiation $(320-400 \mathrm{~nm})$. UV-B radiation $(280-320 \mathrm{~nm})$, which has potentially damaging effects on seedlings (Briggs and Christie, 2002; Schulze et al., 2005), is eliminated by the recycled plastic in even greater percentages; as can be seen in Fig. 9, blends with $90 \mathrm{wt} \%$ of recycled plastic do not show appreciable transmission in that spectral region. Transmission in the blue region of the spectrum, which is important for the development of the seedlings (Lambers et al. 2008; Brown et al., 1995), decreases significantly, although to a lesser extent than the transmission of UV light.

Fig. 10 confirms that the transmission in the visible region of the spectrum is less affected by the addition of recycled plastics, especially in the red region $(600-700 \mathrm{~nm})$, of critical importance for photosynthesis. However, it is necessary to analyze the small transmission differences that appear even within the red region, because each wavelength in this region could cause a different effect on the growth of the seedlings. Several studies have investigated the importance of the red/far-red (R-FR) ratio, which measures the intensity in the far red, about $730 \mathrm{~nm}$, compared to the intensity in the middle red, about $660 \mathrm{~nm}$ (Warrington et al., 1988). In this work, the R-FR ratio has been calculated according to Eq. 1, where $T$ is the percent transmittance at the corresponding wavelength.

$$
R-F R=\frac{T_{660}}{T_{730}}
$$




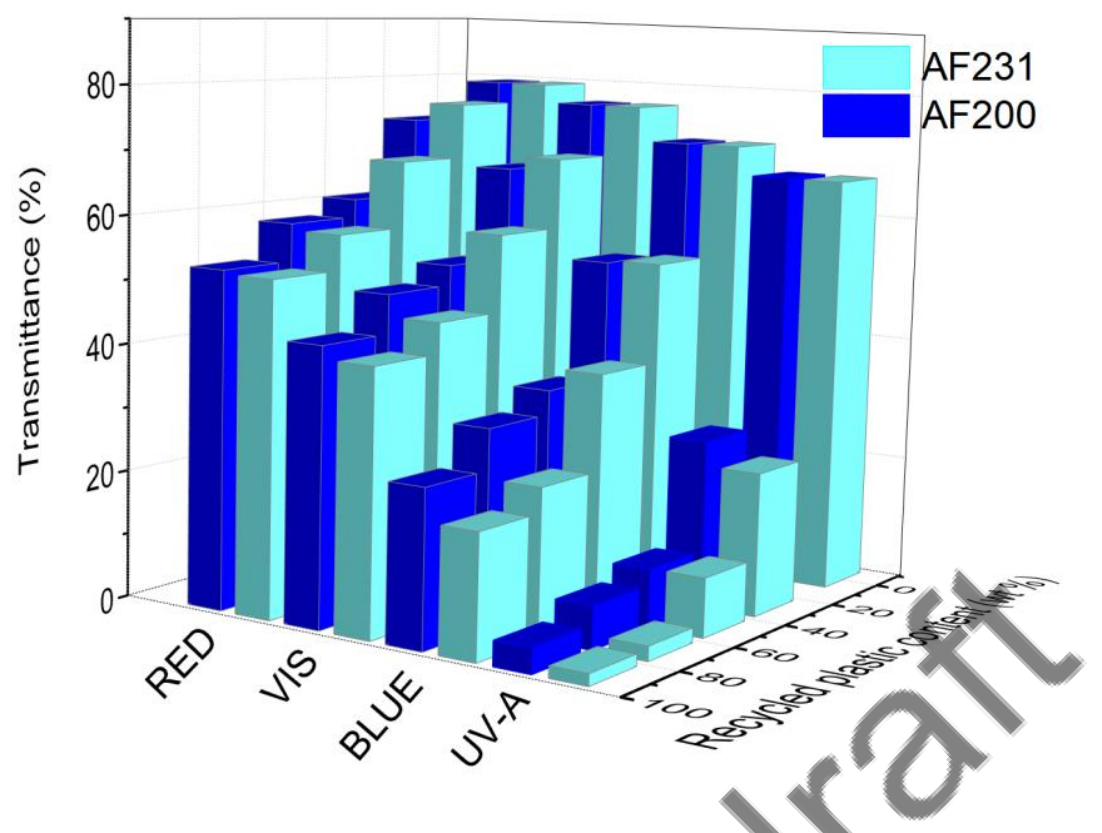

Fig. 10. Effects of recycled agricultural plastics on the light transmission of LDPE.

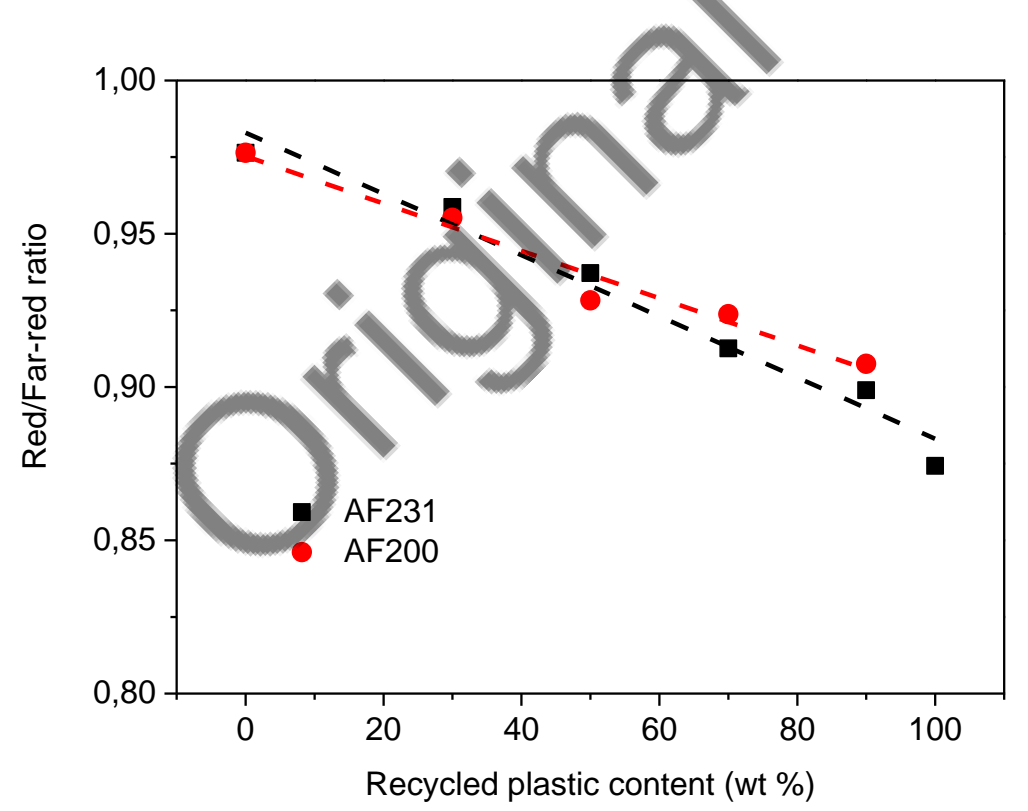

Fig. 11. Effect of recycled plastics on the R-FR ratio. Dashed lines are the best linear fits.

The use of recycled plastic also modifies the Red/Far-red ratio, which has sometimes been used to analyze the suitability of the existing radiation for the development of the seedlings. However, as can be seen in Fig. 11, the effect of recycled plastics is small and the reduction in the R-FR ratio is less than $10 \%$ even in samples with $90 \mathrm{wt} \%$ of recycled plastic.

Fig. 10 and 11 indicate that both the light transmissions in the red and visible spectral regions and the R-FR ratio decrease linearly as the content of recycled plastics increases. Moreover, the effects on the optical properties of the two recycled plastics studied, AF200 and 
AF231, are very similar, as it has been also observed in the mechanical and thermal properties of the blends.

The above results reveal that the blends with low contents of recycled agricultural plastic show photosynthetically active radiation transmissions similar to that of virgin plastic. However, the potentially damaging UV-B radiation is mostly blocked. These results, together with those obtained in the study of stability and mechanical properties, indicate that it is possible to use recycled agricultural plastics to obtain blends with similar properties, or even better in some cases, to those of virgin LDPE, which could be used in the manufacture of protective tubes and related applications. In this way, it would be possible to use significant amounts of agricultural plastics waste in a similar application to that of virgin plastic, thus contributing to achieve the objectives of circular economy policies. The viability of using other recycled plastics, such as polypropylene and poly (lactic acid) (PLA) in this type of applications, will be analyzed in subsequent works.

\section{Conclusions}

Two recycled agricultural plastics and their blends with a virgin low-density polyethylene have been characterized in order to evaluate the feasibility of using the recycled plastics in the manufacture of tube shelters. The main constituents of the recycled plastics are low-density polyethylene, linear low-density polyethylene, ethylene-vinyl acetate copolymer, additives remaining from the original plastics and impurities. The two recycled plastics are dark brown due to the presence of impurities and low amounts of black agricultural plastics.

Regarding the effects on the key properties of the blends, it has been observed firstly that the two starting recycled agricultural plastics behave similarly. The stability of the blends during the accelerated aging test is similar to that of virgin polyethylene; only slight decreases in light transmission and mechanical properties were observed. The thermal stability of the blends is even higher than that of virgin polyethylene, possibly due to the presence of stabilizing additives remaining from the virgin agricultural plastic. The addition of recycled plastic does not significantly reduce the breaking strength of polyethylene, but the elongation at break is reduced by up to $30 \%$, due to the presence of impurities. The effect on the transmission of light, which plays a fundamental role in the growth of the seedling inside the protective tube, depends on the spectral region considered. While transmission in the ultraviolet (UV-A and UV-B) is severely reduced by the use of recycled plastic, transmission in the red region is reduced to a much smaller extent. Finally, it is important to note that the use of recycled plastics in moderate proportions, for example $30 \mathrm{wt} \%$, leads to very small decreases in both the transmission of visible light and the elongation at break, while blocking most of the UV-B radiation. Summarizing, the results obtained in this work indicate that the properties of blends with moderate contents of recycled agricultural plastic are similar to those of virgin plastic, so these blends could meet the specifications for materials in applications such as the manufacture of tube shelters. Therefore, significant amounts of recycled agricultural plastics could be used in this manufacturing, as well as in other similar applications, thus contributing to the development of a circular economy.

\section{Acknowledgements}

The authors would like to acknowledge the financial support of MINECO-Spain (project CTM2017-88989-P) and Universidad Politécnica de Madrid (project UPM RP 160543006). This project has received funding from the European Union's Horizon 2020 research and innovation program under grant agreement No. 860407 BIO-PLASTICS EUROPE. 


\section{References}

ANAIP, 2019. La Plasticultura en https://www.anaip.es/images/Divisiones/Agricultura/Catlogo-La-Plasticultura-en-EspaaANAIP-3-Mb.pdf (accessed March 2019).

Andreoni, V., Saveyn, H.G.M., Eder, P., 2015. Polyethylene recycling: waste policy scenario analysis for the EU-27. J. Environ. Manage. 158, 103-110

Arenas-Vivo, A., Beltrán, F. R., Alcázar, V., de la Orden, M. U., Martinez Urreaga, J., 2017. Fluorescence labeling of high density polyethylene for identification and separation of selected containers in plastics waste streams. Comparison of thermal and photochemical stability of different fluorescent tracers. Mater. Today Comm. 12, 125-132

Briggs, W. R., Christie, J. M., 2002. Phototropins 1 and 2: versatile plant blue-light receptors. Trends in Plant Sci. 7, 204-210

Brown, C. S., Schuerger, A. C., Sager, J. C., 1995. Growth and photomorphogenesis of pepper plants under red light-emitting diodes with supplemental blue or far-red lighting. J. Amer, Soc. Hort. Sci. 120, 808-813

Chuang, T. H., Guo, W., Cheng, K. C., Chen, S. W., Wang, H. T., Yen, Y. Y., 2004. Thermal Properties and Flammability of Ethylene-Vinyl Acetate Copolymer/Montmorillonite/Polyethylene Nanocomposites with Flame Retardants. J. Polym. Res. 11, 169-174

Devine, W., Harrington, C.A., 2008. Influence of four tree shelter types on microclimate and seedling performance of Oregon white oak and western red cedar. Research Paper PNW-RP576. USDA Forest Service, Pacific Northwest Research Station. https://www.fs.usda.gov/treesearch/pubs/30417 (accessed March 2019).

Ellen MacArthur Foundation, 2016. The New Plastics Economy: Rethinking the Future of Plastics. https://www.ellenmacarthurfoundation.org/publications/the-new-plastics-economyrethinking-the-future-of-plastics (accessed March 2019).

European Commission, 2018. A European Strategy for Plastics in a Circular Economy. http://eur-lex.europa.eu/legalcontent/EN/TXT/?qid=1516265440535\&uri=COM:2018:28:FIN (accessed March 2019).

González-Sánchez, C., Martínez-Aguirre, A., Pérez-García, B., Martínez Urreaga, J., de la Orden, M.U., Fonseca-Valero, C., 2014. Use of residual agricultural plastics and cellulose fibers for obtaining sustainable eco-composites prevents waste generation. J. Clean. Prod. 83, 228237

Gu, F., Guo, J., Zhang, W., Summers, P.A., Hall, P., 2017. From waste plastics to industrial raw materials: A life cycle assessment of mechanical plastic recycling practice based on a realworld case study. Sci. Total Environ. 601-602, 1192-1207

Hou, P., Xu, Y., Taiebat, M., Lastoskie, C., Miller, S. A., Xu, M., 2018. Life cycle assessment of end-of-life treatments for plastic film waste. J. Clean. Prod. 201, 1052-1060

Hundertmark, T., Mayer, M., McNally, C., Simons, T. J., Witte, C., 2018. How plastics waste recycling could transform the chemical industry. McKinsey \& Co. https://www.mckinsey.com/industries/chemicals/our-insights/how-plastics-waste-recyclingcould-transform-the-chemical-industry (accessed March 2019).

La Mantia, F. P., 2010. Closed-loop recycling. A case study of films for greenhouses. Polym. Degrad. Stab. 95. 285-288 
1 Lambers, H., Chapin, F.S., Pons, T.J., 2008. Plant physiological ecology (second edition). 2 Springer. New York.

Leal Filho, W., Saari, U., Fedoruk, M., Iital, A., Moora, H., Klöga, M., Voronova, V., 2019. An overview of the problems posed by plastic products and the role of extended producer responsibility in Europe. J. Clean. Prod. 214, 550-558

Martínez Urreaga, J., González- Sánchez, C., Martínez-Aguirre, A., Fonseca-Valero, C., Acosta, J., de la Orden, M.U., 2015. Sustainable eco-composites obtained from agricultural and urban waste plastic blends and residual cellulose fibers. J. Clean. Prod. 108, 377-84

Nature Comm. (Editorial), 2018. Nature Comm. 9: 2157. DOI: 10.1038/s41467-018-04565-2

Oliet, J.A., Planelles, R., Artero, F., Jacobs, D.F., 2005. Nursery fertilization and tree shelters affect long-term field response of Acacia salicina Lindl. planted in Mediterranean semiarid conditions. Forest Ecol. Manag. 215, 339-351

Oliet, J.A., Vázquez de Castro, A., Puértolas, J., 2015. Establishing Quercus ilex under mediterranean dry conditions: sowing recalcitrant acorns versus planting seedlings at different depths and tube shelter light transmissions. New Forests 46, 869-883

Picuno, P., Sica, C., Laviano, R., Dimitrijevic, A., Scarascia-Mugnozza, G, 2012. Experimental tests and technical characteristics of regenerated films from agricultural plastics. Polym. Degrad. Stab. 97, 1654-1661

Plastics Europe, 2018. Plastics - the Facts 2018. An analysis of European plastics production, demand and waste data. https://www.plasticseurope.org/en/resources/publications/619plastics-facts-2018 (accessed March 2019).

Puértolas, J., Oliet, J.A., Jacobs, D.F., Benito, L.F., Peñuelas, J.L., 2010. Is light the key factor for success of tube shelters in forest restoration plantings under Mediterranean climates? Forest Ecol. Manag. 260, 610-617

Ragossnig, A. M., Schneider, D. R., 2019. Circular economy, recycling and end-of-waste. Waste Manag. Res. 37, 109-111

Rentizelas, A., Shpakova, A., Masek, O., 2018. Designing an optimised supply network for sustainable conversion of waste agricultural plastics into higher value products. J. Clean. Prod. $189,683-700$

Scarascia-Mugnozza, G., Sica, C., Russo, G., 2011. Plastic materials in European agriculture: Actual use and perspectives. J. Agric. Eng. - Riv. di Ing. Agr. 3, 15-28

Scoponi, M., Cimmino, S., Kaci, M., 2000. Photo-stabilisation mechanism under natural weathering and accelerated photo-oxidative conditions of LDPE films for agricultural applications. Polymer 41, 7969-7980

Schulze, E.D., Beck, E., Müller-Hohenstein, K., 2005. Plant Ecology. Springer, Berlin

Tzankova Dintcheva, N., Jilov, N., La Mantia, F. P., 1997. Recycling of plastics from packaging. Polym. Degrad. Stab. 57, 191-203

Vallés-Lluch, A., Contat-Rodrigo, L., Ribes-Greus, A., 2002. Degradation studies of LDPEMater-Bi blends annealed and aged in soil. J. Appl. Polym. Sci. 86, 405-413

Vázquez de Castro, A., Oliet, J. A., Puértolas, J., Jacobs, D. F., 2014. Light transmissivity of tube shelters affects root growth and biomass allocation of Quercus ilex L. and Pinus halepensis Mill. Annals of Forest Sci. 71, 91-99 
Warrington, I. J., Rook, D. A., Morgan, D. C., Turnbull, H. L., 1988. The influence of simulated 2 shadelight and daylight on growth, development and photosynthesis of Pinus radiata, Agathis 3 australis and Dacrydium cupressinum. Plant, Cell and Environment 11, 343-356

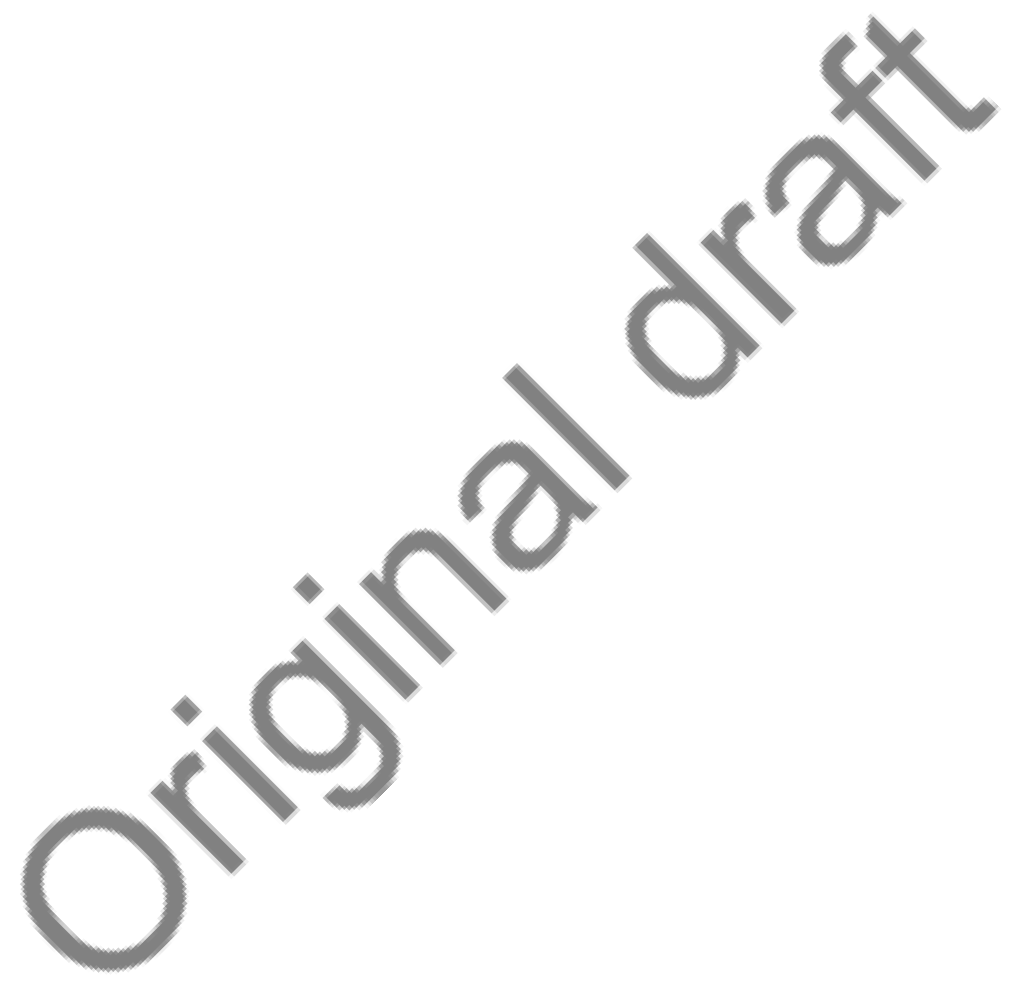

